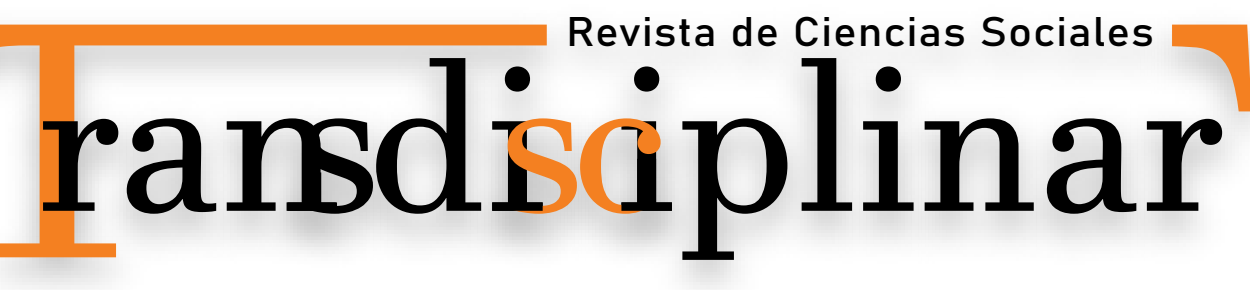

Vol.1 Núm. 1 Julio-Diciembre 2021
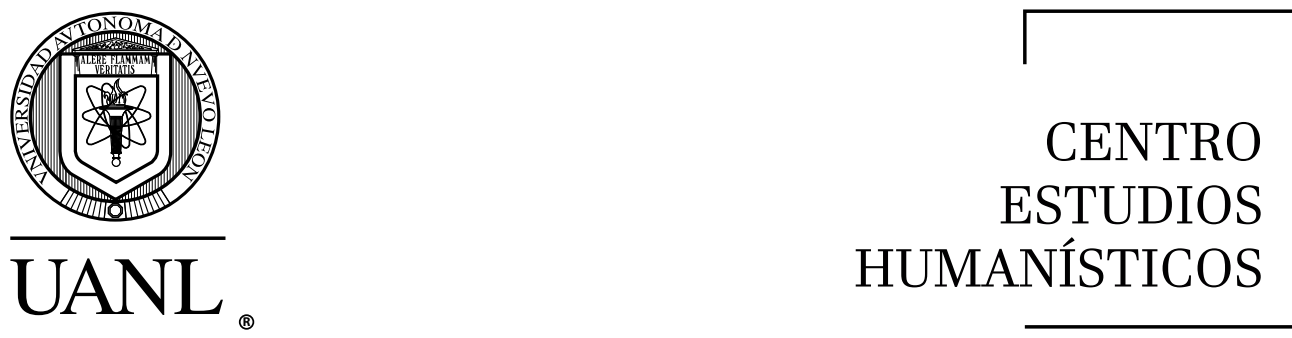


\section{Transdisciplinar \\ Revista de Ciencias Sociales}

El refugio y el procedimiento de solicitud de la condición de refugiado en México

The asylum and the procedure for applying for asylum status in Mexico

Socorro Arzaluz

El Colegio de la Frontera Norte https://orcid.org/0000-0002-3216-0813

Gabriela Zamora

Casa Monarca. Ayuda Humanitaria al migrante https://orcid.org/0000-0001-9798-1973

Fecha entrega: 11-8-2021 Fecha aceptación: 16-8-2021

Editor: Beatriz Liliana De Ita Rubio. Universidad Autónoma de Nuevo León, Centro de Estudios Humanísticos, Monterrey, Nuevo León, México.

Copyright: $\odot 2021$, Arzaluz Socorro. This is an open-access article distributed under the terms of Creative Commons Attribution License [CC BY 4.0], which permits unrestricted use, distribution, and reproduction in any medium, provided the original author and source are credited.

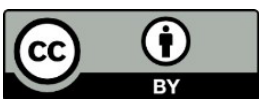

DOI: https://doi.org/10.29105/transdisciplinarl.1-2

Email: sarzaluz@colef.mx / gabriela_zamora@hotmail.com 


\title{
El refugio y el procedimiento de solicitud de la con- dición de refugiado en México
}

\section{The asylum and the procedure for applying for asylum status in Mexico}

Socorro Arzaluz. ${ }^{1}$

sarzaluz@colef.mx

\author{
Gabriela Zamora. ${ }^{2}$ \\ gabriela zamora@hotmail.com
}

Resumen: En México, una serie de instancias y ordenamientos legales determinan la condición de persona refugiada. Se observa que en años recientes han aumentado en forma drástica esta clase de solicitudes. En ese sentido, el objetivo del documento es presentar de manera breve los principales instrumentos jurídicos que se observan para que una persona obtenga el estatus de refugiado. También se determinan a las principales instituciones que cumplen diferentes tareas a lo largo del proceso. Es de esperar que ante el éxodo de las personas de sus lugares de origen debido a la violencia y otras condiciones contempladas en la ley mexicana, la tendencia siga en aumento por lo que es importante difundir el camino a seguir y dar a conocer a los principales actores que intervienen en este proceso.

1 El Colegio de la Frontera Norte.

2 Casa Monarca. Ayuda Humanitaria al migrante. 
Palabras clave: migración, refugio, México

\begin{abstract}
In Mexico, a number of instances and legal systems determine asylum status. It is noted that in recent years these kinds of applications have increased dramatically. In this sense, the objective of the document is to briefly present the main legal instruments that are observed for a person to obtain asylum status. The main institutions that perform different tasks throughout the process are also determined. It is to be expected that in the face of the exodus of people from their places of origin due to violence and other conditions covered by the law, the trend will continue to increase so it is important to spread the way forward and publicize the main actors involved in this process
\end{abstract}

Key words: Migration, asylum, Mexico 


\section{Introducción}

En el ámbito de los derechos humanos, independientemente de la condición de estancia, el Estado Mexicano reconoce los derechos y las garantías para su protección, favoreciendo la defensa más amplia. El Estado Mexicano ha ratificado todos los instrumentos del Sistema Universal y del Sistema Interamericano de Derechos Humanos, en los que se reconoce el derecho a la migración y de las personas migrantes.

Temas como: 1) el reconocimiento de los derechos y obligaciones, 2) la protección de los derechos humanos, 3) el ejercicio de los derechos y la gestión de la migración en México, se plasman en el marco jurídico y normatividad en materia migratoria establecidos en los siguientes instrumentos: 1) la Constitución Política de los Estados Unidos Mexicanos; 2) la Ley General de Población, el 3) Reglamento a la Ley General de Población; 4) la Ley de Migración; 5) el Reglamento a la Ley de Migración, 6) los Lineamientos para Trámites y Procedimientos Migratorios; 7) la Ley sobre Refugiados, Protección Complementaria y Asilo Político; 8) el Reglamento a la Ley sobre Refugiados, Protección Complementaria y Asilo Político; 9) la Ley de Nacionalidad y 10) el Reglamento de la Ley de Nacionalidad.

\section{Actores y proceso para la obtención del refugio}

El ejercicio y gestión de la política migratoria tienen impacto en otras legislaciones de carácter general que, en su conjunto, integran el marco constitucional y legal en que se fundamenta la política y gestión migratoria en México (UPM, 2013). En este tenor, las legislaciones mencionadas dan cuenta de la formalización de 
los derechos de las personas migrantes y refugiadas definiendo asimismo las diferentes condiciones, derechos y mandato de la política migratoria y de refugio mexicana. La figura 1 muestra las normatividades, las dependencias responsables de conducir las políticas en la materia y las condiciones facultadas a otorgar.

Figura 1.

Instrumentos jurídicos para la gestión de la migración en México

\begin{tabular}{|c|c|c|c|}
\hline \multicolumn{4}{|c|}{$\leftarrow$ Constitución Política de los Estados Unidos Mexicanos $\rightarrow$} \\
\hline \multirow{5}{*}{$\begin{array}{l}\text { Secretaría } \\
\text { de } \\
\text { Gobernación } \\
\text { (SEGOB) }\end{array}$} & Responsable & Corpus legislativo & $\begin{array}{c}\text { Condiciones facultadas a } \\
\text { otorgar }\end{array}$ \\
\hline & $\begin{array}{l}\text { Registro Nacional de } \\
\text { Población (RENAPO) }\end{array}$ & $\begin{array}{l}\text { - Ley General de } \\
\text { Población } \\
\text { - Reglamento de la } \\
\text { Ley General de } \\
\text { Población }\end{array}$ & $\begin{array}{l}\text {-Clave Única del Registro } \\
\text { de Población (CURP) }\end{array}$ \\
\hline & $\begin{array}{l}\text { Instituto Nacional de } \\
\text { Migración (INM) }\end{array}$ & $\begin{array}{l}\text {-Ley de Migración } \\
\text {-Reglamento de la Ley de } \\
\text { Migración } \\
\text {-Lineamientos para } \\
\text { Trámites y } \\
\text { Procedimientos } \\
\text { Migratorios }\end{array}$ & $\begin{array}{l}\text {-Condiciones de legal } \\
\text { estancia } \\
\text {-Determinación de } \\
\text { apatridia }\end{array}$ \\
\hline & $\begin{array}{l}\text { Comisión Mexicana } \\
\text { de Ayuda a Refugiados } \\
\text { (COMAR) }\end{array}$ & $\begin{array}{l}\text {-Ley sobre Refugiados, } \\
\text { Protección } \\
\text { Complementaria } \\
\text { y Asilo Político } \\
\text { - Reglamento de la Ley } \\
\text { sobre Refugiados, } \\
\text { Protección } \\
\text { Complementaria y Asilo } \\
\text { Político }\end{array}$ & $\begin{array}{l}\text { - Condición de refugiado } \\
\text {-Protección } \\
\text { complementaria }\end{array}$ \\
\hline & $\begin{array}{l}\text { Secretaría de Relaciones } \\
\text { Exteriores (SRE) }\end{array}$ & $\begin{array}{l}\text {-Ley de Nacionalidad } \\
\text {-Reglamento de la Ley de } \\
\text { Nacionalidad }\end{array}$ & -Asilo político \\
\hline
\end{tabular}

Fuente: Elaboración propia con información de las legislaciones mencionadas. 
En el ámbito de la protección internacional, la Ley sobre Refugiados, Protección Complementaria y Asilo Político, se centra en tres figuras: refugio, protección complementaria y asilo político. Además de contener los elementos de la Convención sobre el Estatuto de los Refugiados de 1951 y su Protocolo de 1967, considera entre los supuestos los incluidos en la Declaración de Cartagena sobre Refugiados. En su artículo 13 la Ley sobre Refugiados, Protección Complementaria y Asilo Político (LSRPCyAP) establece que:

La condición de refugiado se reconocerá a todo extranjero que se encuentre en territorio nacional, bajo alguno de los siguientes supuestos:

I. Que debido a fundados temores de ser perseguido por motivos de raza, religión, nacionalidad, género, pertenencia a determinado grupo social u opiniones políticas, se encuentre fuera del país de su nacionalidad y no pueda o, a causa de dichos temores, no quiera acogerse a la protección de tal país; o que, careciendo de nacionalidad y hallándose, a consecuencia de tales acontecimientos, fuera del país donde antes tuviera residencia habitual, no pueda o, a causa de dichos temores, no quiera regresar a él;

II. Que ha huido de su país de origen, porque su vida, seguridad o libertad han sido amenazadas por violencia generalizada, agresión extranjera, conflictos internos, violación masiva de los derechos humanos u otras circunstancias que hayan perturbado gravemente el orden público, y

III. Que debido a circunstancias que hayan surgido en su país de origen o como resultado de actividades realizadas, du- 
rante su estancia en territorio nacional, tenga fundados temores de ser perseguido por motivos de raza, religión, nacionalidad, género, pertenencia a determinado grupo social u opiniones políticas, o su vida, seguridad o libertad pudieran ser amenazadas por violencia generalizada, agresión extranjera, conflictos internos, violación masiva de los derechos humanos u otras circunstancias que hayan perturbado gravemente el orden público

La definición expuesta en la legislación además de progresista, brinda la oportunidad de protección a mayor número de personas puesto que contempla como solicitante de la condición de refugiado al extranjero que independientemente de su situación migratoria solicita el reconocimiento de la condición de refugiado y reconoce con la condición de refugiado a la persona "que ha huido de su país de origen, porque su vida, seguridad o libertad han sido amenazadas por violencia generalizada, agresión extranjera, conflictos internos, violación masiva de los derechos humanos u otras circunstancias que hayan perturbado gravemente el orden público" (LSRPCyAP, artículo 13).

En México la Comisión de Ayuda a Refugiados (COMAR) es la autoridad competente en materia de refugio, de acuerdo con lo establecido en la LSRPCyAP y su Reglamento, cualquier extranjero que, encontrándose en territorio nacional, tiene derecho a solicitar que le sea reconocida la condición de refugiado.

El procedimiento de solicitud y reconocimiento de la condición de refugiado (figura 2) implica presentar en un período de hasta 30 días hábiles, la solicitud ante la Coordinación General de la COMAR o ante INM, quien en estos casos deberá canalizar 
la solicitud a la Coordinación General. En la solicitud se deben incluir todos los familiares que acompañan a la persona solicitante previa acreditación del vínculo familiar. Las solicitudes también pueden llevarse a cabo posterior al período estipulado, no obstante, el solicitante debe explicar a detalle el motivo que le impidió la presentación.

\section{Figura 2.}

Procedimiento del trámite de solicitud de la condición de refugiado.

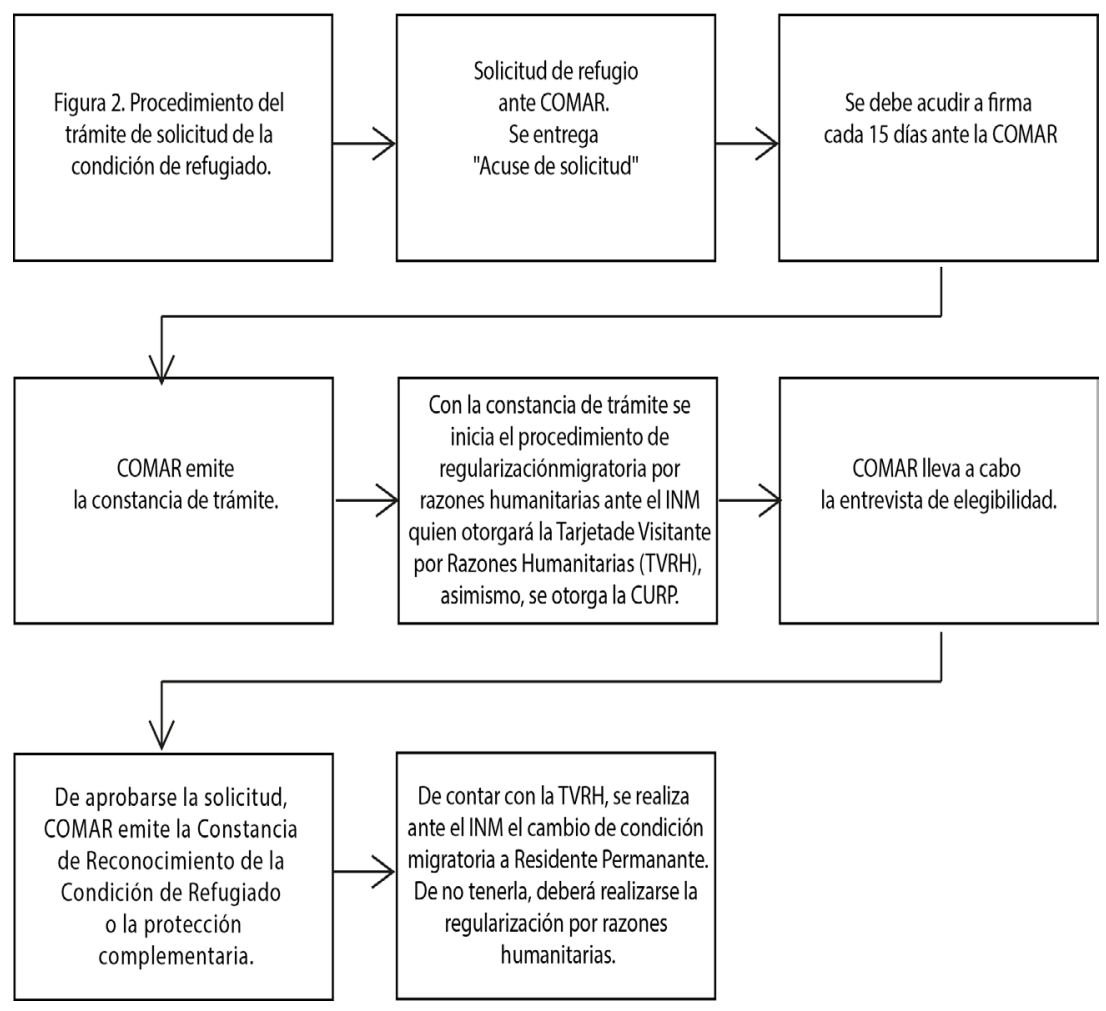

Fuente: Elaboración propia con información de la Comisión Mexicana de Ayuda a Refugiados (COMAR) y el Alto Comisionado de las Naciones Unidas para los Refugiados (ACNUR). 
Recibida formalmente la solicitud, la COMAR emite un acuse de solicitud y con ello prueba el inicio del procedimiento y garantiza la no devolución de la persona a su país de origen o al lugar en donde su vida, seguridad o libertad son amenazadas. Una vez tramitada la solicitud, la COMAR expide un documento "Constancia de Trámite con Respecto de la Solicitud del Reconocimiento de la Condición de Refugiado" que comprueba que el procedimiento de solicitud se encuentra en curso.

A partir de ese momento todos los solicitantes deben permanecer en la entidad federativa en donde le fue otorgado el trámite a la solicitud, salvo autorización expresa de la COMAR ya que, de no hacerlo, el caso se da por abandonado. Para probar la estancia, la persona debe acudir cada 15 días a las oficinas de la COMAR o del INM donde presentó la solicitud a firmar una constancia de permanencia en el estado, práctica que ha sido suspendida indefinidamente por la contingencia sanitaria.

Una vez obtenida la Constancia de Trámite con Respecto de la Solicitud del Reconocimiento de la Condición de Refugiado, la persona podrá obtener su Clave Única de Registro de Población (CURP) y adicionalmente iniciar ante el Instituto Nacional de Migración (INM) su regularización migratoria por razones humanitarias, resultado del trámite, se obtendrá la "Tarjeta de Visitante por Razones Humanitarias", que permite residir y trabajar legalmente en México durante el trámite.

Como parte del procedimiento, la COMAR solicita una entrevista a los peticionarios para conocer si la vida, seguridad o libertad de la persona corre riesgo de regresar al país de origen. Por lo que además del llenado del cuestionario la COMAR realizará 
una entrevista personal para conocer los motivos por los cuales se solicita la protección. Durante la entrevista el solicitante debe narrar los hechos en los que basa su solicitud y aportar el mayor número de detalles posibles por los que no puede regresar a su país.

Posterior a la entrevista de elegibilidad, la COMAR lleva a cabo una investigación y análisis del caso en el que recopila la opinión de la Secretaría de Relaciones Exteriores, información objetiva de fuentes confiables, y en caso de ser necesario del Alto Comisionado de las Naciones Unidas para los Refugiados (ACNUR). Para la obtención del resultado la COMAR tiene hasta 55 días hábiles después de la fecha marcada en la constancia, 45 días hábiles para emitir una resolución fundada y motivada respecto del reconocimiento o no de la condición de refugiado, más 10 días para informar el resultado. En algunos casos, la COMAR puede ampliar el plazo por otros 45 días hábiles.

De reconocerse el refugio, la COMAR entregará la "Constancia de Reconocimiento de la Condición de Refugiado” al solicitante y a todos los familiares incluidos en la solicitud. En el supuesto de no reconocerse la condición de refugiado, la COMAR en la misma resolución debe pronunciarse en el sentido de otorgar o no otorgar la protección complementaria.

En los casos en que la resolución de COMAR sea negativa, la persona tiene el derecho a presentar una apelación dentro de los 15 días hábiles siguientes a la notificación. Posteriormente, la COMAR revisará el caso por segunda ocasión, si la COMAR otorga una segunda negativa, el extranjero tiene derecho a continuar la apelación ante un juez, si se opta por la no revisión, la persona debiera retornar a su país. 
Con relación a la condición de estancia migratoria, el INM documentará al extranjero bajo la calidad de inmigrado y si previamente cuenta con una condición de estancia por razones humanitarias podrá realizar su cambio de condición migratoria a "Residente Permanente", de lo contrario, deberá realizar la Regularización por Razones Humanitarias.

Solicitar asilo es un derecho consagrado en el artículo 14 de la Declaración Universal de los Derechos Humanos, no obstante, el trámite de la solicitud de refugio es vinculado a la regularización migratoria de la persona, que a su vez depende de la resolución emitida por la COMAR organismo encargado de la política de refugio en México. Es facultad del INM la regularización migratoria y en el caso de las personas con necesidad de protección internacional, les permite regularizar su situación migratoria por razones humanitarias a fin de permanecer en México, misma que acredita a la persona a obtener la Tarjeta de Visitante por Razones Humanitarias y con esta la regular estancia, así como el acceso a derechos, entre otros, el empleo formal.

\section{Referencias}

Alto Comisionado de las Naciones Unidas para los Refugiados (ACNUR). (2021). ¿Cómo solicitar ser refugiado en México? https://help.unhcr.org/mexico/como-solicitar-la-condicion-de-refugiado-en-mexico/

Cámara de Diputados del H. Congreso de la Unión. (21/02/12/Texto vigente 2021). Reglamento de la Ley de Refugiados, Protección Complementaria y Asilo Político. México: Diario Oficial de la Federación. Reglamento de la Ley sobre Refugiados y Protección Complementaria (diputados.gob.mx) 
Cámara de Diputados del H. Congreso de la Unión. (27 enero 2011/ 30 octubre 2014 Texto vigente). Ley de Refugiados, Protección Complementaria y Asilo Político. México: Diario Oficial de la Federación. Ley sobre Refugiados, Protección Complementaria y Asilo Político (www.gob. $\underline{\mathrm{mx}}$

Comisión Mexicana de Ayuda a Refugiados (COMAR). (2021). Procedimiento para el reconocimiento de la condición de refugiado. http://www.comar.gob.mx/es/COMAR/ Procedimiento para ser reconocidos

(26 mayo 2011/ 20 mayo 2021) Ley de Migración. Ley de Migración (cndh.org.mx)

Organización de las Naciones Unidas ONU). (2015). Declaración Universal de los Derechos Humanos. UDHR booklet SP web.pdf (un.org)

Secretaría de Gobernación (SEGOB). (08/11/12). LINEAMIENTOS para trámites y procedimientos migratorios. México: Diario Oficial de la Federación. http://dof.gob.mx/ nota detalle.php?codigo=5276967\&fecha=08/11/2012

Secretaría de Gobernación (SEGOB). Unidad de Política Migratoria, Registro e Identidad de Personas. (UPMRIP). (2013). Legislación migratoria e instrumentos Jurídicos para la gestión de la migración en México. México: Secretaría de Gobernación. Unidad de Política Migratoria (politicamigratoria.gob.mx) 